\title{
A influência das conceções sobre a literacia científica no desenvolvimento da
}

\section{cidadania}

\section{The influence of conceptions of scientific literacy in developing citizenship}

\author{
Luísa Martins*, Jorge Bonito**, Luís Marques*** \\ *CI\&DETS - Instituto Politécnico de Viseu, Portugal, **Universidade de Évora, Portugal, ***Universidade de Aveiro, Portugal
}

\begin{abstract}
Resumo
As caraterísticas da sociedade contemporânea obrigam a uma crescente preocupação com a educação científica, de modo a preparar cidadãos participantes, críticos e responsáveis. No presente trabalho pretende-se discutir alguns dos resultados de um estudo no âmbito da educação em Geociências, diagnosticando a importância atribuída por alunos do ensino secundário à literacia científica. Foi escolhida uma abordagem metodológica mista, orientada pelo paradigma socio-crítico. Os resultados do estudo realizado mostram que o conhecimento das conceções dos alunos sobre a importância da literacia científica pode fundamentar uma atuação da escola e da sociedade que contribua favoravelmente para o desenvolvimento e valorização da cidadania.
\end{abstract}

Palavras-chave: Literacia científica, Geociências, Cidadania, Conceções.

\begin{abstract}
The characteristics of contemporary society demand a growing concern with scientific education in order to prepare critical active and responsible citizens. In this paper, we intend to discuss some of the results of a study on education in Geosciences, diagnosing the importance given by high school students (16-17 years old) to scientific literacy. A mixed methodological approach was chosen, guided by socio-critical paradigm. The results of the study performed show that knowledge of students' conceptions about the importance of scientific literacy can, thus, support a school's performance and society to contribute favourably to the development and enhancement of citizenship.

Keywords: Science literacy, Geosciences, Citizenship, Conceptions.
\end{abstract}

\section{Introdução}

As questões relacionadas com a literacia científica são objeto de grande atenção por parte dos responsáveis de muitos países e estão na origem da organização de várias iniciativas. Diversos estudos têm identificado problemas preocupantes ao nível da literacia científica (GAVE, 2007). A chamada emergência planetária alerta-nos para a gravidade dos riscos e para os problemas globais com que a humanidade se confronta (Eurostat, 2010; Vilches \& Gil-Pérez, 2008). Ao mesmo tempo, os dados relativos aos jovens em idade escolar que sabem identificar, explicar e aplicar conhecimentos científicos em situações conhecidas e desconhecidas, a par da falta de interesse desses jovens pelo estudo das ciências e, consequentemente, em prosseguir uma carreira dentro da área das ciências podem pôr em causa a qualidade da investigação e a capacidade de inovar (Rocard, 2007). Por outro lado, as caraterísticas da sociedade contemporânea obrigam a uma crescente preocupação com a educação científica, de modo a preparar cidadãos participantes, críticos e responsáveis (Aikenhead, 2009; Martins \& Balula, 2009).

A literacia científica é definida no PISA (OECD, 2014), desde 2007, como

an individual's scientific knowledge, and use of that knowledge, to identify questions, acquire new knowledge, explain scientific phenomena and draw evidence-based conclusions about science-related issues; understanding of the characteristic features of science as a form of human knowledge and enquiry; awareness of how science and technology shape our material, intellectual and cultural environments; and willingness to engage in science-related issues, and with the ideas of science, as a reflective citizen. (p. 216)

Esta definição, comparada com a que era apresentada em 2002 (OECD, 2002), traduz uma evolução, incluindo a referência explícita às questões de cidadania: "and willingness to engage in science-related issues, and with the ideas of science, as a reflective citizen” (p. 102).

Para formar "cidadãos e cidadãs responsáveis, é preciso que lhes proporcionemos ocasiões para analisarem os problemas globais que caraterizam essa situação de emergência planetária e considerar possíveis soluções para eles” (Praia, Gil-Pérez \& Vilches, 2007, p. 145). Todas estas preocupações conduziram a uma confluência nos responsáveis políticos de diferentes países, com contextos educativos muito diferentes, na introdução de orientações relativamente à educação em ciência.

Como dizem Merino e Cerezo (2012), "la ciencia ha sido un importante motor en innumerables avances de las sociedades contemporáneas. Pero para alcanzar tales logros se necesitó del concurso de la sociedad en su conjunto, no solo del trabajo de los científicos e ingenieros” (pp. 54-55).

Perante estes dados, a educação em ciência deve assumir-se como "um fator positivo de compreensão mútua, entre indivíduos e grupos humanos. A sua maior ambição passa a ser a generalização dos meios necessários a uma cidadania consciente e ativa, que só pode realizar-se, plenamente, num contexto de sociedades democráticas” (Delors, 1996, p. 45). Assim, na escola, deve procurar desenvolver-se um trabalho que, para além da aquisição e desenvolvimento de uma atitude democrática, procure "ajudar o aluno a entrar na vida, 
com capacidade para interpretar os factos mais importantes relacionados quer com o seu destino pessoal, quer com o destino coletivo" (Delors, 1996, p. 52). A humanidade reconhece na educação a chave para a resolução de muitos problemas com que nos debatemos atualmente. Por isso, educar constitui um grande desafio e uma grande responsabilidade.

A perspetiva Ciência/Tecnologia/Sociedade (CTS), que surgiu após a Segunda Guerra Mundial, inspirada nas "ideias, princípios e valores inerentes à cidadania democrática e à sua promoção” (Santos, 2004, p. 21), é apontada como uma linha de atuação que apresenta potencialidades para dar resposta aos problemas com que nos deparamos ao nível da educação em ciência das novas gerações. Alguns autores sustentam que é pela abordagem do conhecimento científico "através de problematização contextualizada, que se podem apetrechar os cidadãos com o conhecimento, as capacidades e os valores da ciência e tecnologia para tomarem decisões mais informadas, nos contextos sociais e humanos” (Cachapuz, Paixão, Lopes \& Guerra, 2008, p. 41). Advogam, ainda, que a educação em ciência deve ajudar os cidadãos a compreenderem o mundo em que vivem e que está imerso na ciência, mas também a compreender que existem muitos fatores não científicos, nomeadamente no contexto das aplicações científicas, que contribuem para as tomadas de posição e decisões dos cidadãos, nas matérias científicas e tecnológicas. Destaca-se uma perspetiva que dá predomínio à cultura científica, às interconexões entre a ciência e a sociedade, apontando a necessidade de aumentar a literacia científica dos estudantes e da população em geral.

No presente trabalho, pretende-se discutir alguns dos resultados de um estudo, no âmbito da educação em Geociências, que partiu da seguinte questão: "De que modo a educação em geociências pode contribuir para um aprofundamento da cultura científica e da responsabilidade do cidadão promotor do desenvolvimento sustentável, numa matriz Ciência/Tecnologia/Sociedade?”. Os resultados em análise dizem respeito à importância atribuída por alunos do ensino secundário à literacia científica.

\section{Método}

No estudo desenvolvido, aplicou-se um questionário (TEMGEODS) a alunos do ensino secundário das regiões Norte e Centro de Portugal.

O questionário utilizado na recolha dos dados teve como base a pesquisa realizada no âmbito do projeto Deep time in schooling: contributions of students' perceptions for the development of scientifically literate citizens, do Centro de Investigação Didática e Tecnologia na Formação de Formadores da Universidade de Aveiro (Portugal), e os dados do projeto PISA (OCDE, 2007).

O questionário foi validado com base na aplicação em duas turmas com Biologia e Geologia e na análise efetuada por um grupo de peritos pertencentes a três universidades portuguesas (Universidade do Porto, Universidade de Évora e Universidade de Aveiro) (Martins, 2015).
A aplicação do questionário foi feita em 26 escolas distribuídas por 22 cidades e vilas da região Norte e Centro de Portugal, em Fevereiro e Março de 2010, por um professor de cada uma das turmas, com a supervisão dos autores do estudo, depois de obtida a autorização dos órgãos diretivos para o fazer.

A amostra não probabilística intencional é assim constituída por 74 turmas (26 turmas de alunos do $10{ }^{\circ}$ ano de escolaridade - 15 anos de idade - com Biologia e Geologia, 22 turmas de alunos do $10 .^{\circ}$ ano sem Biologia e Geologia e 26 turmas de alunos do $11 .^{\circ}$ ano de escolaridade - 16 anos de idade - com Biologia e Geologia), tendo sido recolhidas mil seiscentas e quatro (1604) respostas.

Para o tratamento estatístico dos dados relativos às respostas dos alunos, recorreu-se à utilização do SPSS.

\section{Resultados}

A partir da análise e interpretação dos dados relativos às respostas dos alunos ao questionário, vamos fazer a caraterização da amostra do estudo e identificar a importância que os alunos do ensino secundário atribuem à literacia científica, de modo a tirar algumas conclusões para a construção de um quadro teórico que fundamente a promoção do desenvolvimento dos alunos como cidadãos cientificamente cultos, numa lógica de sustentabilidade.

\section{Caraterização da amostra}

A caraterização da amostra, que a seguir apresentamos, é feita a partir da informação fornecida pelas respostas à primeira parte do questionário TEMGEODS. A partir da análise destes dados, pretendeu-se construir uma imagem dos alunos que pudesse ajudar a identificar alguns fatores a ter em conta na interpretação dos dados relativos à importância que os alunos atribuem à literacia científica.

Curso do ensino secundário frequentado. A maioria dos alunos da amostra (72,8\%) frequentava o curso de ciências e tecnologias, seguindo-se os alunos do curso de línguas e humanidades (19,6\%). A amostra era ainda constituída por $6,1 \%$ de alunos que frequentavam o curso de artes visuais, por $0,9 \%$ de alunos que frequentavam o curso profissional de energias renováveis e $0,6 \%$ de alunos que frequentavam o curso de ciências socioeconómicas.

Idade e ano de escolaridade. A maior parte dos alunos tinha idades compreendidas entre os 16 (43,74\%), os $15(39,42 \%)$ e os 17 anos (13,20\%). No 10. ${ }^{\circ}$ ano a maioria dos alunos tinha 15 anos e no $11 .^{\circ}$ ano a maioria tinha 16 anos. Verifica-se assim que a maioria dos alunos inquiridos fez um percurso escolar normal, sem retenções.

Sexo. Relativamente ao sexo, verificámos que a amostra deste estudo é constituída maioritariamente por indivíduos do sexo feminino (56,2\%).

Localidade de residência. Os alunos residem em 22 concelhos, pertencentes a 8 distritos das regiões Norte e Centro de Portugal (NUTS II). Em todos os concelhos há uma percentagem igual ou superior a $2,2 \%$ do total de respondentes. $\mathrm{O}$ concelho com menor percentagem de respondentes é Almeida, no distrito da Guarda. O 
concelho de Viseu é aquele em que há maior percentagem de respostas (14,4\%), seguido dos concelhos da Maia, com 7,7\%, e de Viana do Castelo, com 6\%. Agrupando os concelhos por distritos, verificamos que respondem $35,4 \%$ de residentes no distrito de Viseu, 16,9\% de Aveiro, 15\% da Guarda, 10\% de Braga, 7,7\% do Porto, 6,1\% de Viana do Castelo, $4,5 \%$ de Coimbra e $4,4 \%$ de residentes no distrito de Castelo Branco.

Qualificações académicas dos pais. Verifica-se, também, que a maior parte dos pais dos alunos inquiridos não chegou a ingressar no ensino secundário: 26,6\% dos pais concluíram o segundo ciclo do ensino básico ou equivalente e 24,1\% concluíram o terceiro ciclo do ensino básico ou equivalente. Apenas 19,3\% tinham o curso geral do ensino secundário ou equivalente. Os pais que têm formação ao nível do ensino superior correspondem apenas a 17,2\%.

Relativamente às mães, cerca 24,7\% têm apenas o terceiro ciclo do ensino básico ou equivalente, 23,1\% das mães têm o segundo ciclo do ensino básico ou equivalente. Apenas 19,2\% têm o curso geral do ensino secundário e as mães que têm formação ao nível do ensino superior correspondem a 21,3\%.

Verifica-se, assim, uma ligeira vantagem das qualificações académicas da mãe relativamente às qualificações do pai. Por outro lado, podemos constatar que as qualificações académicas dos pais (pai e mãe) dos respondentes são, em termos globais, mais elevadas do que as médias relativas à totalidade da população portuguesa, segundo os Censos 2001 (INE, 2002, LXVII).

Profissão dos pais e profissões desejadas pelos alunos. As profissões mais representadas, em relação ao pai, dizem respeito às categorias "operários, artífices e trabalhadores similares”, com 25,3\%, "operadores de instalações e máquinas e trabalhadores da montagem”, com 13,4\%, "pessoal dos serviços e vendedores”, com $13,1 \%$ e " especialistas das atividades intelectuais e científicas”, com 12,2\%.

Relativamente à mãe, as profissões com maior representação são as que correspondem às seguintes categorias: "trabalhadores não qualificados/profissões elementares”, com 23,6\%, "pessoal dos serviços e vendedores", com 20,9\%, e "especialistas das atividades intelectuais e científicas”, com 17,2\%. Constata-se ainda que as mães desempregadas (6,1\%) são aproximadamente o dobro relativamente aos pais (3,2\%).

As profissões desejadas pela maioria dos alunos $(72,5 \%)$ inserem se na categoria "profissionais científicos e intelectuais”.

\section{A importância da literacia científica}

Nesta secção, apresenta-se a análise e interpretação da informação obtida a partir das respostas dadas à segunda parte do questionário TEMGEODS, que tem como objetivo identificar a importância que os alunos atribuem à literacia científica.

Da análise em componentes principais da informação recolhida destacaram-se três aspetos: a consciência dos assuntos ambientais; a perspetiva sobre as questões ambientais (otimismo ambiental); e a motivação para o envolvimento com a ciência.

Consciência dos assuntos ambientais. A maioria dos alunos considera conhecer satisfatoriamente ou conhecer muito bem o problema dos gases com efeito de estufa na atmosfera (95,8\%), da destruição das florestas para dar outro uso ao solo $(91,3 \%)$, da sobre-exploração das reservas de petróleo e gás natural (84,5\%), da acumulação de resíduos urbanos (83,7\%) e do bombardeamento meteorítico cíclico (59,9\%). Destacam-se, particularmente, os problemas do aumento dos gases com efeito de estufa na atmosfera e da destruição das florestas para dar outro uso ao solo em que, respetivamente, $48,3 \%$ e $46,1 \%$ dos inquiridos dizem que os conhecem muito bem.

Otimismo ambiental. A maioria dos alunos considera que vão aumentar, ou vão aumentar muito, os problemas relacionados com a extinção das plantas e animais (82,7\%), a escassez de água doce potável (82,7\%), a poluição atmosférica (80\%), os resíduos nucleares $(73,4 \%)$ e com a escassez de energia $(60,4 \%)$. É de salientar, ainda, o facto da escassez de energia ser o problema em relação ao qual a maior percentagem de inquiridos (39,6\%) assinala que vai diminuir ou que vai ficar igual.

Motivação para o envolvimento com a ciência. De modo a identificar a motivação dos alunos para se envolverem com a ciência, procurámos saber qual o seu grau de interesse na aprendizagem de diversas áreas científicas, sobre aspetos relacionados com processos científicos e em relação a afirmações acerca das vantagens de aprender ciências, além do grau de concordância com um conjunto de afirmações sobre a importância da ciência.

Relativamente ao grau de interesse na aprendizagem de diversas áreas científicas, a maioria dos inquiridos afirma que se interessa ou que se interessa muito pelo estudo da Biologia Humana (74,7\%), da Geologia (54,7\%), da Química (53,7\%) e da Biologia Vegetal (52,9\%). Por outro lado, a maioria dos alunos diz que não se interessa ou que se interessa pouco pelo estudo da Astronomia (51,7\%) e da Física (50,3\%).

Em relação aos aspetos relacionados com processos científicos, a maioria dos alunos diz interessar-se ou interessar-se muito pelo modo como os cientistas concebem as experiências (73,5\%) e pelos aspetos relacionados com o que é preciso para que uma explicação seja considerada científica (57,9\%). Contudo, a percentagem de alunos que manifesta interessar-se pouco ou manifesta desinteresse $(26,5 \%$ relativamente à conceção das experiências e 42,1\% relativamente aos requisitos das explicações científicas) é demasiado elevada, tendo em conta as caraterísticas da amostra em estudo. A informação conduz-nos à constatação de que uma grande parte dos alunos diz concordar parcialmente ou em absoluto com a afirmação de que o esforço que é despendido para aprender vai ajudar na profissão que querem vir a ter $(93,5 \%)$, com a possibilidade das aprendizagens em ciências poderem aumentar as 
alternativas futuras de trabalho (84,2\%) e com a utilidade pessoal do estudo das ciências (79,6\%). A maioria dos inquiridos reconhece, ainda, a importância do estudo da ciência para ajudar a compreender a natureza (94,6\%). Cerca de 94\% afirma concordar (parcialmente ou em absoluto) com a utilidade da ciência para a sociedade, com a possibilidade do progresso científico e tecnológico trazer benefícios sociais $(91,1 \%)$ e benefícios económicos (89,8\%).

\section{Literacia Científica versus Variáveis Demográficas e Escolares}

O elevado tamanho da amostra permite-nos apelar ao teorema do limite central, ou teorema de Lindberg-Levy, que estabelece que, em amostras grandes, a distribuição tende para a normalidade (Murteira, Ribeiro, Silva \& Pimenta, 2001).

$\mathrm{Na}$ matriz de correlações entre as variáveis de importância da literacia científica, é analisada apenas a magnitude da correlação. Para um $\mathrm{N}$ grande, por exemplo de 1000, são significativas correlações superiores a 0,052 para $\mathrm{p}<0,05$ e superiores a 0,062 para $\mathrm{p}<0,01$. Como a correlação é sensível ao tamanho da amostra, para amostras grandes uma correlação pode ser estatisticamente significativa, mas sem significado substantivo. Tomando o exemplo anterior, uma correlação de 0,052 significa que as variáveis possuem uma variância comum de 0,0522 (ou seja, 0,27\%). Seguimos o critério de Cohen (Cohen \& Manion, 1990) e consideramos uma correlação inferior a 0,30 pequena, entre 0,30 e 0,50 moderada e superior a 0,50 elevada.

Tabela 1.

Matriz de correlações entre as medidas de importância atribuída à literacia científica.

\begin{tabular}{lcccc}
\hline $\begin{array}{l}\text { Importância da literacia } \\
\text { científica (ILC) }\end{array}$ & $\begin{array}{c}\text { ILC_- } \\
\text { CAA }\end{array}$ & $\begin{array}{c}\text { ILC_ } \\
\text { OA }\end{array}$ & $\begin{array}{c}\text { ILC_I } \\
\text { APC }\end{array}$ & $\begin{array}{c}\text { ILC_I } \\
\text { AC }\end{array}$ \\
\hline $\begin{array}{l}\text { ILC_CAA Consciência dos } \\
\text { assuntos ambientais }\end{array}$ & 1 & & & \\
$\begin{array}{l}\text { ILC_OA Otimismo ambiental } \\
\begin{array}{l}\text { ILC_IAPC Interesse pelas } \\
\text { áreas e processos científicos }\end{array}\end{array}$ & 0,137 & 1 & & \\
$\begin{array}{l}\text { ILC_IAC Importância } \\
\text { atribuída à ciência }\end{array}$ & 0,347 & 0,118 & 1 & \\
\hline
\end{tabular}

A consciência dos assuntos ambientais obtém uma correlação moderada com o interesse pelas áreas e processos científicos $(0,347)$ e com a importância atribuída à ciência $(0,396)$. Um maior interesse pelas áreas e processos científicos está associado à importância atribuída à ciência com uma correlação elevada $(0,555)$.

Para testar a diferença entre médias, é considerada a prova estatística ANOVA. É sempre testada a homocedasticidade através do teste de Levene e sempre que se verifica heterocedasticidade é considerada a correção de Brown-Forsythe.

Sexo. Rapazes e raparigas não se distinguem, em média, na consciência dos assuntos ambientais. O otimismo ambiental é significativamente superior nas raparigas em comparação com os rapazes. Também o interesse pelas áreas científicas é estatisticamente superior no sexo feminino. São as raparigas, ainda, que atribuem maior importância à ciência, sendo a diferença entre médias estatisticamente significativa.

Idade e ano de escolaridade. A idade não se correlaciona com qualquer das medidas da importância atribuída à literacia científica.

Na consciência dos assuntos ambientais, os jovens do $10 .^{\circ}$ ano que não frequentam a disciplina de Biologia e Geologia apresentam uma média significativamente inferior aos seus colegas que a frequentam no $10 .^{\circ}$ e no 11. ${ }^{\circ}$ anos.

A perspetiva otimista sobre as questões ambientais (otimismo ambiental) entre os alunos do $10 .^{\circ}$ ano que não frequentam a disciplina de Biologia e Geologia apresenta a média inferior. $\mathrm{O}$ valor da média aumenta nos alunos do $10 .^{\circ}$ ano e do $11 .^{\circ}$ ano que a frequentam. A diferença entre médias é estatisticamente significativa entre os jovens do $10 .^{\circ}$ ano que não frequentam a disciplina de Biologia e Geologia o os do $11 .^{\circ}$ ano que frequentam essa disciplina.

O interesse pelas áreas e processos científicos é superior nos alunos do $11 .^{\circ}$ ano e $10 .^{\circ}$ ano que frequentam a disciplina de Biologia e Geologia relativamente aos do $10 .^{\circ}$ ano que não frequentam a disciplina. Os alunos do $10 .^{\circ}$ ano que frequentam a disciplina de Biologia e Geologia não se distinguem, em média, dos seus colegas do $11 .^{\circ}$ ano.

A importância atribuída à ciência pelos alunos do $10{ }^{\circ}$ ano que não frequentam a disciplina de Biologia e Geologia é estatisticamente inferior à que é atribuída pelos seus colegas do $10 .^{\circ}$ e do $11 .^{\circ}$ ano que frequentam essa disciplina.

Qualificações académicas dos pais. Para ser possível efetuar a estatística inferencial na comparação dos resultados dos sujeitos relativamente ao nível de escolaridade dos seus pais, foi necessário recodificar as habilitações, de forma a obter um menor número de categorias. As formações de nível III e de nível IV foram agregadas com o ensino secundário.

A consciência dos assuntos ambientais cresce, em média, à medida que a escolaridade dos pais também cresce. Porém, as diferenças observadas não são estatisticamente significativas.

Também não têm expressão estatística as diferenças observadas entre as médias na perspetiva otimista sobre as questões ambientais (otimismo ambiental).

A importância atribuída à ciência é superior nos filhos de pais com ensino secundário relativamente aos filhos de pais com "outra” habilitação ou com o 2. ${ }^{\circ}$ ciclo do ensino básico.

Os filhos de pais com qualificação académica ao nível do ensino superior ou do ensino secundário apresentam médias estatisticamente superiores, relativamente àqueles cujos pais têm “outra” qualificação, no interesse pelas áreas e processos científicos.

A consciência dos assuntos ambientais é superior nos filhos de mães com formação ao nível do ensino superior relativamente aos seus colegas cujas mães têm como habilitações o $2 .^{\circ}$ ciclo ou o $3 .^{\circ}$ ciclo do ensino básico. 
A perspetiva otimista sobre as questões ambientais (otimismo ambiental) não varia estatisticamente em função das habilitações da mãe.

O interesse pelas áreas e processos científicos é superior nos filhos de mães com habilitações de nível superior quando comparados com os filhos de mães com 3. ${ }^{\circ}$ ciclo, 2. ${ }^{\circ}$ ciclo ou "outra” habilitação.

São também os filhos de mães com formação ao nível do ensino superior, aqueles que atribuem mais importância à ciência. A diferença é estatisticamente significativa relativamente aos $3 .^{\circ}$ e $2 .^{\circ}$ ciclos do ensino básico.

\section{Discussão}

Os resultados do estudo realizado mostram que os alunos consideram conhecer bem os problemas ambientais que lhes são apresentados. Os resultados indicam também que a consciência dos assuntos ambientais é influenciada pela frequência da disciplina de Biologia e Geologia e pela qualificação académica mais elevada (ao nível do ensino superior) das mães. As expectativas sobre a possibilidade de os problemas ambientais serem solucionados nos próximos vinte anos são superiores no sexo feminino e nos alunos do $10 .^{\circ}$ ano sem a disciplina de Biologia e Geologia. Relativamente à motivação para o envolvimento com a ciência, os resultados apontam que o interesse pelas áreas e processos científicos é superior nos indivíduos do sexo feminino, nos alunos com a disciplina de Biologia e Geologia e nos filhos de pais com qualificação académica ao nível do ensino superior. Verifica-se ainda que a importância atribuída à ciência é maior nas raparigas, nos alunos que frequentam durante mais tempo as aulas de Biologia e Geologia e nos filhos de pais com qualificações académicas superiores. O conhecimento das conceções dos alunos sobre a importância da literacia científica pode, assim, fundamentar uma atuação da escola e da sociedade que contribua favoravelmente para o desenvolvimento e valorização da cidadania.

\section{Referências}

Aikenhead, G. (2009). Educação Científica para todos. Mangualde: Edições Pedago.

Cachapuz, A., Paixão, F., Lopes, J., \& Guerra, C. (2008). Do estado da arte da pesquisa em educação em ciências: linhas de pesquisa e o caso "Ciência-Tecnologia-Sociedade". ALEXANDRIA Revista de Educação em Ciência e Tecnologia, 1(1), 25-46.

Cohen, L., \& Manion, L. (1990). Métodos de Investigación Educativa. Madrid: Editorial La Muralla.

Delors, J. (1996). Educação: Um tesouro a descobrir. Relatório para a UNESCO da Comissão Internacional sobre Educação para o século XXI. Porto: ASA.

Eurostat (2010). Combating poverty and social exclusion - A statistical portrait of the European Union 2010. Luxembourg: European Commission.

GAVE (2007). PISA 2006 - Competências científicas dos alunos portugueses. Lisboa: Ministério da Educação.
INE - Instituto Nacional de Estatística (2002). Censos 2000 - Resultados Definitivos. XIV Recenseamento Geral da População. IV Recenseamento Geral da Habitação. Lisboa: INE.

Martins, L. (2015). Contributos da educação em Geociências para o desenvolvimento sustentável: uma abordagem ao tempo geológico (Tese de doutoramento). Universidade de Aveiro, Aveiro.

Martins, L., \& Balula, J. (2009). A interdisciplinaridade na formação de cidadãos cientificamente cultos: um caso de implementação do projeto "Jovens repórteres para o ambiente”. In F. Paixão \& F. Jorge (Coord.), Educação e Formação - Ciência, Cultura e Cidadania. Atas XIII Encontro Nacional de Educação em Ciências, (pp. 1138-1149). Castelo Branco: Escola Superior de Educação do Instituto Politécnico de Castelo Branco.

Merino, N., \& Cerezo, J. (2012). Cultura científica para la educación del siglo XXI. Revista Iberoamericana de Educación, 58, 35-59.

Murteira, B., Ribeiro, C., Silva, J., \& Pimenta, C. (2001). Introdução à estatística. Lisboa: Mc Graw-Hill.

OCDE (2007). PISA 2006 - Competências Científicas dos Alunos Portugueses. Lisboa: GAVE - Ministério da Educação.

OECD (2002). Sample tasks from the PISA 2000 Assessment. Reading, Mathematical and Scientific Literacy. Paris: OECD Publications.

OECD (2014). PISA 2012 Results: What students know and can do - Student performance in Mathematics, Reading and Science (Volume I, Revised edition, February 2014). PISA: OECD Publications.

Praia, J., Gil-Pérez, D., \& Vilches, A. (2007). O papel da Natureza da Ciência na Educação para a Cidadania. Ciência \& Educação, 13(2), 141-156.

Rocard, M. (Coord.) (2007). Science Education now: a renewed pedagogy for the future of Europe. Brussels: European Commission.

Santos, M. (2004). Dos códigos de cidadania aos códigos do movimento CTS. Fundamentos, desafios e contextos. In I. Martins, F. Paixão e R. Vieira (Eds.), Perspetivas ciência-tecnologia-sociedade na inovação da educação em ciência (pp. 13-22). Aveiro: Universidade de Aveiro.

Vilches, A., \& Gil-Pérez, D. (2008). La construcción de un futuro sostenible en un planeta en riesgo. Alambique. Didáctica de las ciencias experimentales, 55(Enero), 9-19. 